\title{
O CORPO VIVIDO E O MOVIMENTO DA VIDA EM M. MERLEAU-PONTY E R. BARBARAS
}

=

Esteban A. García*

Resumo: As análises aqui propostas enfocam, em primeira instância, a leitura do corpus merleau-pontiano, proposta por R. Barbaras em seu Introduction à une phénoménologie de la vie, segundo a qual os vaivens e ambivalências da reflexão de Merleau-Ponty acerca do corpo se explicam pela desconsideração de seu caráter primordialmente vivente. Em segundo lugar, abordamos a filosofia de Merleau-Ponty a partir do propósito de encontrar no corpo uma modalidade originária e absoluta de movimento como abertura de possibilidades, fundante em relação ao objeto que se move e ao espaço, aberto pelo próprio movimento. Em terceiro lugar, pondo em relevo a noção de nascimento, propomos que esta singular modalidade de movimento buscada por Merleau-Ponty encontra sua caracterização mais apropriada no movimento natural e vital, o que permite conciliar, ao menos parcialmente, as perspectivas de ambos os filósofos.

Palavras-chave: Merleau-Ponty, Barbaras, movimento, vida, corporalidade.

Todo o percurso da reflexão merleau-pontiana foi marcado pelo propósito dominante de elucidar o singular modo de ser de nossa corporeidade, que o filósofo caracterizou, desde sua Fenomenologia da Percepção, como "ambíguo". Segundo observa lucidamente R. Barbaras em sua Introduction à une phénoménologie de la vie, uma dificuldade chave com que se depara essa empresa é o fato de que nossa experiência corporal conjuga duas condições ao mesmo tempo irrecusáveis e difíceis de conciliar: nosso pertencimento ao mundo e nossa distância frente a

* Tradução de Silvana de Souza Ramos.

** Universidad de Buenos Aires - Consejo Nacional de Investigaciones Científicas y Técnica. E-mail: baneste72@gmail.com. 
ele, como sujeitos que percebem. Nosso corpo resume o paradoxo de que uma parte do mundo possa ser ao mesmo tempo consciente do mundo. A leitura de Barbaras põe em relevo de maneira certeira as contradições, as ambivalências e os vaivens do corpus merleau-pontiano em sua dificuldade para encontrar uma caracterização sui generis desse modo original de ser que é próprio ao corpo. Em sua visão, as aporias da busca merleaupontiana só poderiam ser contornadas abordando-se o corpo vivido como corpo vivente, vislumbrando-o assim desde a perspectiva mais originária do movimento da vida. Nas páginas seguintes nos propomos encontrar no próprio Merleau-Ponty o esboço de uma definição original do corpo em termos de uma modalidade particular do movimento, que em última instância poderá ser caracterizada - em termos quiçá próximos de alguns dos propostos por Barbaras - como movimento vital.

\section{A indefinição do corpo e os vaivens do corpus merleau-pontiano segundo a leitura de R. Barbaras}

$\mathrm{Na}$ Fenomenologia da Percepção, Merleau-Ponty pretendia haver encontrado - ou ao menos estar em busca de - uma dimensão ontológica original distinta do modo de ser do sujeito e do objeto no modo de ser do corpo: tratava-se de encontrar "entre o puro sujeito e o objeto um terceiro gênero de ser" (Merleau-Ponty 9, p. 402). Contudo, de acordo com a leitura proposta por R. Barbaras em sua Introduction à une phénoménologie de la vie, naquela obra o corpo não é tematizado por si mesmo e não recebe uma caracterização positiva como "outro tipo de ser" singular, mas cumpre a única função de adjetivar ou de qualificar a consciência: a corporeidade equivale, em última instância, meramente à passividade da consciência. Nas palavras de Barbaras:
O corpo próprio permanece aí pensado a partir da consciência e finalmente abordado como uma modalidade daquela, [...] como uma consciência opaca e incoativa. [...] Nisto, Merleau-Ponty não ultrapassa verdadeiramente a concepção metafísica do corpo como aquele que vem borrar ou obscurecer a transparência da Razão (Barbaras 1, p. 71).

Ora, de acordo com essa mesma interpretação, quando MerleauPonty quer fazer valer a corporalidade contra o modelo de uma consciência transcendental e constituinte, devedor direto de uma definição intelectualista da consciência, refere-se então ao corpo em sua materialidade física ou em suas definições anátomo-fisiológicas. Deste modo, as análises merleaupontianas passariam diretamente ou sem escalas de um corpo-sujeito - ou, mais estritamente, um sujeito encarnado - ao lado contrário, isto é, a um corpo objetivado pelas ciências da vida e vice-versa, em um movimento de vaivém ou zigue-zague que nunca encontraria esse "outro tipo de ser" onde deter - ou começar - uma análise original e própria do corpo vivente enquanto tal. Neste sentido, na Fenomenologia da Percepção conviveriam problematicamente a corporalidade como adjetivação de uma consciência que agora se "encarnou" e "a ideia do corpo, que é ainda própria da Fenomenologia da Percepção, como fragmento de extensão habitado por uma sensibilidade" (Barbaras 1, p. 78). Em apoio a esta avaliação de Barbaras, poderiam ser recordadas aquelas afirmações de Merleau-Ponty na Fenomenologia da Percepção que aludiam ao fato de que:

um homem sem mãos ou sem sistema sexual é tão inconcebível quanto um homem sem pensamento. [...] É impossível distinguir no ser total do homem uma organização corpórea (...) dos demais predicados. Não é por mera coincidência que o ser razoável é também o que está de pé ou possui um polegar oposto aos demais dedos (Merleau-Ponty 10, p. 187). 
Nesta passagem, como em outras, parece patente que naquelas ocasiões em que a Fenomenologia da Percepção pretende reivindicar com maior intensidade "a organização corpórea" frente ao pensamento intelectualista recorre às definições anátomo-fisiológicas mais clássicas da corporalidade.

Essa justaposição de uma consciência racional (mesmo que já qualificada como carnal) e um corpo anátomo-fisiológico, essa ambivalência que consiste em afirmar ao mesmo tempo e alternativamente um e outro, sem poder encontrar aí, apesar das intenções explícitas do autor, passagem, uma tematização positiva do corpo vivente como núcleo desde o qual os dois termos da oposição derivariam, pode revelarse também claramente na conhecida análise do membro fantasma. Ali “o movimento da existência" ou o "ser-no-mundo" são os emblemas de "um terceiro tipo de ser" ambíguo, próprio de uma redefinição sui generis do corpo, e, contudo, no final do capítulo em questão (o primeiro da parte I da Fenomenologia da Percepção) essa existência volta na análise a desdobrar-se em uma consciência racional e voluntária, por um lado, e em um conjunto de processos fisiológicos, por outro. Assim, depois de situar a chave da compreensão do fenômeno no corpo vivido já definido além de sua objetivação científica como um repertório de possibilidades de comportamento sedimentadas pelo hábito, ao perguntar-se por que a secção dos nervos pode ocasionalmente suprimir a experiência do membro fantasma, Merleau-Ponty volta a invocar o clássico fator neurofisiológico: "Desde nosso ponto de vista, um circuito sensório-motor é, no interior de nosso ser-no-mundo global, uma corrente de existência relativamente autônoma" (Merleau-Ponty 10, p. 105). Neste contexto se pode encontrar também uma confirmação do "vaivém", advertido por Barbaras, nas palavras mesmas de Merleau-Ponty quando afirma que "o homem concretamente tomado não é um psiquismo relacionado a um organismo, mas este vaivém da existência que ora se deixa ser corpórea e ora remete aos atos pessoais" (Merleau-Ponty 10, p. 107).

Se Merleau-Ponty segue mantendo, mesmo a contragosto, o conceito de um corpo que está no mundo como uma parte deste, porém, ao mesmo tempo, pode ter o mundo à distância (ao ser consciente dele na percepção), o corpo não faz mais que batizar o problema da insuficiência de cada uma das duas perspectivas e a simultânea necessidade de ambas. Seria por um motivo semelhante que Merleau-Ponty desenvolve tardiamente uma ontologia da carne, já não entendida como esse "fragmento de matéria circunscrito" ao "qual um sentir viria misteriosamente agregar-se" (Barbaras 1, pp. 66, 67), definição que poderia convir ao corpo, mas como "um modo de ser caracterizado pela identidade do sentir e do pertencimento, identidade da qual meu corpo é como o emblema ou a manifestação, mas que não pode confundir-se com ele" (Barbaras 1, p. 77). Assim, na interpretação de Barbaras, a qual estamos recolhendo, a última filosofia de Merleau-Ponty sustentaria a seguinte tese: "não é porque meu corpo está no mundo (posição espacial) que ele é do mundo (parentesco ontológico); é, pelo contrário, na medida em que é do mundo [relação de pertença e continuidade ontológica a que alude a figura da carne] que pode estar também no mundo" no modo do corpo ou de "minha carne" (Barbaras 1, p. 77). Segundo essa visão, a virada ontológica da reflexão merleau-pontiana significaria uma radicalização e inclusive uma inversão do ponto de vista priorizado na Fenomenologia da Percepção. A encarnação da consciência operada naquela obra significava uma "mundanização" do sujeito que agora, por sua vez, é vista como fundada no ser carnal do corpo e seu originário pertencimento ao mundo, de tal modo que "o devir mundo do sujeito [é agora entendido como] o devir fenomenal do mundo". Nas palavras de Barbaras:

O caminho de Merleau-Ponty consiste portanto em radicalizar a passividade do sentir, sua inscrição num corpo, compreendendo-a como filiação ontológica, o que conduz 
a por em evidência uma sorte de inversão intencional: se o sentir está verdadeiramente imerso no mundo (imersão carnal da qual o corpo é a atestação), então o sentir do mundo (pelo sujeito) se confunde com a vinda do mundo ao parecer, quer dizer, com seu ser sentido. O verdadeiro sujeito do sentir não é mais o corpo, como na Fenomenologia da Percepção, mas o mundo mesmo, do qual o corpo se destaca: o sentir é sentir do mundo no duplo sentido do genitivo (Barbaras 1, p. 79).

Em contraste com a Fenomenologia da Percepção e sua adjetivação corporal do sujeito, é a subjetividade mesma a que agora porta um mero sentido adjetivo, como "ser subjetivo ou fenomenal do mundo" (Barbaras 1, p. 79). Essa interpretação é confirmada pela taxativa afirmação de Merleau-Ponty correspondente a uma nota de trabalho inédita citada por Barbaras em Le tournant de l'expérience: "Nossa corporeidade: não colocála no centro como fiz na Fenomenologia da Percepção: num sentido, ela é apenas a dobradiça do mundo" (Barbaras 2, p. 217).

Embora Merleau-Ponty, em outra nota de trabalho inédita citada por Barbaras (desta vez em Introduction à une phénoménologie de la vie), advirta sobre a necessidade de não cair no "monismo explicativo" de uma "ontologia intermediária", a carne como visibilidade do mundo que reúne em si mesma a visão e o visto, o sujeito e o objeto, parece funcionar como chave de uma sorte de "filosofia monista da natureza" tal como a que se pretende evitar. ${ }^{1}$ Desde esta perspectiva, o corpo parece diluir-se no "anonimato" primordial da carne e, segundo a fala de Barbaras, "se torna impensável" (Barbaras 1, p. 8). Ora, como adverte o próprio filósofo, isto não é o que sempre de fato sucede nos escritos incluídos no Visivel e o Invisivel, ao contrário, o corpo próprio, meu corpo ou minha carne são invocados de modo intermitente para desenhar ou atenuar esta tendência monista até o ponto de fazer retroceder a análise, ocasionalmente, até o subjetivismo que caracterizava o Merleau-Ponty de 1945: "A carne do mundo não é um sentir-se como minha carne - Ela é sensível e não sentiente", lê-se ainda nas notas de trabalho do Visível e o Invisível (Merleau-Ponty 11, p. 304). Em passagens como esta, a carne parece referir-se com propriedade somente ao meu corpo e se estender somente de modo metafórico para aludir à "carne do mundo", desfazendo-se assim o caminho andado e reiterando-se as mesmas aporias que, como MerleauPonty mesmo advertia em algumas de suas notas de trabalho, eram próprias ao ponto de vista da Fenomenologia da Percepção em seu compromisso com o lastro das filosofias da consciência e do sujeito. ${ }^{2}$

Barbaras conclui sua leitura do percurso reflexivo merleau-pontiano indicando que os vaivens, ambivalências e aporias que o atravessam não se justificam, mas se explicam, porém, quando se recorda que o problema do qual parte o filósofo é o da consciência perceptiva em sua diferença para com a consciência intelectual, à qual usualmente se subordinou ou se reduziu a análise da primeira, e o corpo funciona como resposta a essa pergunta. Assim, “o corpo não é interrogado por si mesmo, em seu sentido de ser próprio, mas como o que organiza a receptividade da consciência e, por isso, a opacidade do objeto percebido". A fenomenologia merleau-pontiana, em suma, "não é uma fenomenologia do corpo, mas da percepção" (Barbaras 1, pp. 82, 83). Esse modo de ser próprio do corpo que a filosofia havia deixado escapar, na proposta de Barbaras, não se revela mediante a equívoca referência à carne, mas é o próprio da vida: “O Leib [...] deve ser compreendido do ponto de vista do Leben", o viver que anima a carne e que funda conjuntamente o pertencimento ao mundo e sua percepção (Barbaras 1, p. 84). No entanto, poderemos perguntar nas seções seguintes deste trabalho se o próprio Merleau-Ponty não outorga ao corpo uma caracterização original e específica que se relaciona justamente, em última instância, com o movimento vital que lhe é próprio, tal como o exige Barbaras. 
Antes de propor algumas alternativas à proposta de interpretação de Barbaras recém resumida, é possível fornecer outros elementos que confirmam aquela remissão - em retrocesso - que acertadamente observa o filósofo, desde a ontologia merleau-pontiana da carne até as teses mais básicas da fenomenologia anterior, do corpo próprio. Pode-se ler, por exemplo, nas notas finais do Visível e o Invisível:

eu não posso por um único sensível sem pô-lo como arrancado à minha carne, colhido da minha carne, e a minha própria carne é um dos sensíveis no qual se faz uma inscrição de todos os outros, sensível pivô (...) Meu corpo é no mais alto grau aquilo que qualquer coisa é: um isto dimensional. É a coisa universal - Mas enquanto as coisas só se tornam dimensões a partir do momento em que são recebidas no interior de um campo, o meu corpo é este campo, (...) medidor universal (Merleau-Ponty 11, p. 313). ${ }^{3}$

Nas últimas notas se torna evidente que longe de diluir-se no ser de indivisão, e mesmo longe da perfeita simetria especular entre a carne do mundo e minha carne que algumas passagens parecem evocar, o corpo-objeto é ainda pensado como realidade sensível chave, o eixo, a medida universal ou "o visível arquétipo" (Merleau-Ponty 11, p. 326). O fato de que meu corpo seja visível tal como o que ele vê, acrescenta Merleau-Ponty, "não quer dizer simplesmente: é um pedaço do visível", porque "meu corpo é passivo-ativo (visível-vidente)" (Merleau-Ponty 11, pp. 324, 325). Segundo o filósofo, é somente em função dessa particularidade de meu corpo como sentiente-sensível que o mundo pode tornar-se sensível: o corpo como "sensível exemplar", "ele e somente ele, porque é um ser de duas dimensões, pode nos levar às coisas mesmas" (Merleau-Ponty 11, p. 179). ${ }^{4}$

Certamente, essa distinção recém estabelecida entre o corpo como sentiente-sensível e o mundo como somente sensível parece debilitar-se em certos parágrafos nos quais Merleau-Ponty radicaliza as consequências do enraizamento carnal. Assim, pode ler-se, por exemplo, que "a visão que ele [o vidente] exerce, sofre-a também por parte das coisas"; "eu me sinto olhado pelas coisas (...) de sorte que vidente e visível se fazem recíprocos e já não se sabe quem vê e quem é visto" (Merleau-Ponty 11, p. 183). Antes de precisar o alcance dessas afirmações, podemos recordar que sua aparente radicalidade não supera o que já era sugerido pela Fenomenologia da Percepção, quando Merleau-Ponty sustentava que o céu que percebo é "para si": quando vejo o céu, o céu "se pensa em mim"; "eu sou o próprio céu que se reúne, se recolhe e se põe a existir para si" (Merleau-Ponty 9, p. 248). No Visível e o Invisível as frases antes citadas, que descrevem o movimento do sentir como proveniente do visível, situam-se num contexto em que a pergunta se o entrelaço é total e implica uma identidade absoluta ou se implica uma identidade "parcial" ou "diferenciada" é deixada em suspenso: "Não examinaremos por ora até onde vai essa identidade do vidente e do visível" (Merleau-Ponty 11, p. 177). Quando, na continuação, o filósofo introduz em sua análise os outros corpos percipientes, volta a se referir ao que chamava metaforicamente de "o olhar do mundo" para mostrar que não se trata de um verdadeiro olhar, pois não equivale ao olhar de um corpo. O olhar das coisas é agora redefinido como "Um olhar sem pupila, o espelho sem amálgama das coisas, esse pálido reflexo, esse fantasma de nós mesmos, que elas evocam ao designar um lugar entre elas desde o qual as vemos". Somente quando outro corpo sentiente-sensível aparece, acrescenta Merleau-Ponty, "pela primeira vez o vidente que sou me é verdadeiramente visível”, indicando que o mundo não é sentiente no mesmo patamar que o corpo (Merleau-Ponty 11, pp. 188, 189). Não se formula então uma simples identidade entre essas dimensões da carne, que são meu corpo e o mundo, ao contrário, é necessário para o filósofo continuar distinguindo-as e mostrando ao mesmo tempo que só existem em seu entrelaço mútuo. Estes textos do filósofo mostram com evidência que a última ontologia merleau-pontiana da carne não significa um total 
abandono ou ruptura com relação a uma filosofia do sujeito que se acharia na Fenomenologia da Percepção. Por um lado, esta obra não propõe uma simples reivindicação subjetivista, mas sim uma crítica do sujeito clássico tendo em vista sua condição corporal. E, por outro lado, esse sujeito corporal já debilitado naquela obra não desaparece no Visivel e o Invisivel, mas, pelo contrário, constitui um elemento de referência constante e explícita na ontologia da carne. ${ }^{5}$ Se é assim, as primeiras e as últimas expressões do filosofar merleau-pontiano não colocam uma alternativa tão excludente como a que ocasionalmente observa Barbaras, já que em ambos os casos se busca revelar o mesmo entrelaçamento ontológico do sujeito percipiente com o mundo, relação que implica uma redefinição do primeiro dos termos, porém, em nenhum caso, sua elisão.

\section{O movimento do corpo vivido como fundante do móvel e do espaço}

Ora, reconhecido esse parentesco ou continuidade entre as primeiras e as últimas formulações do filósofo, é possível ainda tomar outras distâncias com relação à leitura esboçada por Barbaras, propondo uma chave alternativa de interpretação. Se é verdade que frequentemente o corpo da Fenomenologia da Percepção parece ziguezaguear entre as opções da mera adjetivação ou qualificação da consciência e de sua materialidade física ou anátomo-fisiológica, pode advertir-se que o corpo recebe uma descrição original e própria em termos de um tipo peculiar de movimento, uma maneira própria de mover-se. Precisamente a isto se refere a definição central da Fenomenologia da Percepção do corpo vivido como esquema motriz, que a leitura de Barbaras aparentemente não considera de maneira afirmativa, como uma abordagem do modo de ser do corpo por si mesmo. O corpo vivido, definido na Fenomenologia da Percepção como movimento, não está no espaço como um corpo físico ou como o corpo anátomo-fisiológico, tampouco está fora do espaço como uma consciência que o sobrevoaria como totalidade inteligível, ele "faz" espaço ou "abre" o espaço: a isto se refere o tópico merleau-pontiano da "profundidade" enquanto espacialidade originária, existencial e ontológica, que estabelece o movimento corporal e constitui a raiz subjacente da espacialidade pensada e da espacialidade física.

A seção da segunda parte da Fenomenologia da Percepção referida ao movimento parece buscar a definição de um tipo singular de movimento que define o corpo vivido, distinguindo-o de todo movimento no espaço enquanto sistema da exterioridade, porém, sem ser por isso desligado da espacialidade. Aalternativa às definições físicas empiristas e intelectualistas do movimento é perseguida segundo uma estratégia característica de toda a obra, recorrendo a uma descrição fenomenológica do movimento tal como é diretamente vivido e percebido. Para Descartes, quando algo se movimenta significa propriamente que se move "da vizinhança" de alguns corpos "que parecem em repouso" à vizinhança de outros (Descartes 4, Parte III). Algo se move em relação a outra coisa que parece permanecer no lugar, embora este segundo objeto também possa ser considerado como estando em movimento em relação a um terceiro que não observamos. Nossa experiência comum do movimento das coisas e de nós mesmos e nosso sentido usual do termo "mover-se" são, desta perspectiva, alusões equívocas a fragmentos do circuito completo do verdadeiro movimento circular que anima uniformemente todos os corpos: "nenhum corpo pode mover-se senão em círculo" por consequência lógica direta do corpuscularismo com plenum do sistema cartesiano (Descartes 4, p. 57). Se entendemos o espaço no sentido transcendental kantiano, devemos também renunciar a nossas concepções e percepções mais básicas e comuns do que chamamos "movimento": neste caso, os objetos se movem sem propriamente subir nem descer, sem se aproximar ou se distanciar, sem ir 
à esquerda ou à direita, a não ser em relação a algum outro objeto tomado como referência. Essas definições relativas do movimento são as únicas que autorizam as concepções objetivas do espaço. Contudo, elas não somente anulam os traços mais elementares de nossa experiência de mover e de perceber o movimento das coisas, como também fazem definitivamente do movimento um fenômeno enganoso e até meramente presuntivo: uma mudança de relações entre objetos que seria experimentada de outro modo e até mesmo desapareceria se variassem os pontos de referência ou a área de observação. Aquilo a que estas análises não fazem justiça é então, em primeira instância, ao fato mesmo de que o movimento seja imediatamente vivido e percebido como um fenômeno positivo que consta em nossa experiência enquanto tal. Nos termos da Fenomenologia da Percepção:

Se o movimento não segue sem uma referência exterior (...) não há meio de atribuí-lo ao móvel mais que à referência, (...) não há movimento absoluto. Não obstante, este pensamento do movimento é uma negação do movimento. (...) $\mathrm{O}$ movimento não é uma hipótese cuja probabilidade venha medida, como na teoria física, pelo número de fatos que coordena. Isto somente forneceria um movimento possível. O movimento é um fato. A pedra não é pensada, mas vista em movimento (Merleau-Ponty 10, pp. 283, 281).

Dar crédito à realidade do movimento significa então, para Merleau-Ponty, afirmar a existência de um movimento absoluto, quer dizer, não relativo a uma referência exterior variável. De certo modo, Husserl em escritos tais como A Terra não se move havia advertido sobre a insuficiência das definições relativas do movimento: é necessário contar com um "aqui”" absoluto fornecido pela Terra como solo do corpo próprio em relação ao qual se pode medir o repouso e o movimento relativo de todos os outros corpos (Husserl 6). Ora, para ser "absoluto" este "aqui" não pode ser, por sua vez, somente um lugar localizado no espaço. Neste sentido, antes de ocupar um lugar o corpo próprio é um "poder mover-se" que dá lugar ao corpo que se move no espaço e o "faz" lugar: abre o espaço mesmo, desdobra-o desde um "aqui" particular, o qual não é possível localizar no espaço, como mais um lugar entre os outros. Assim, observa Merleau-Ponty, "se tenho meu braço encima da mesa nunca me ocorrerá dizer que ele esteja ao lado do cinzeiro, como este está ao lado do telefone" (Merleau-Ponty 10, p. 115). Mais geralmente, pode-se dizer que "a palavra 'aqui' aplicada ao meu corpo não designa uma posição determinada em relação a outras posições ou em relação a coordenadas exteriores, mas sim a instalação das primeiras coordenadas, a ancoragem do corpo ativo em um objeto, a situação do corpo perante suas tarefas" (Merleau-Ponty 10, p. 117). Mover-se neste sentido mais primário e original do movimento não é passar de um lugar a outro, mas abrir o espaço de tal modo que haja um lugar onde apoiar-se, desde onde partir e até onde ir, um lugar adiante e outro atrás: este movimento real abre o espaço do movimento possível. Resulta assim mesmo significativa a qualificação de "germinal" aplicada por Merleau-Ponty à "originalidade dos movimentos que executo com meu corpo" e às "sensações cinestésicas", no momento de relacionálos com o movimento no espaço objetivo: "há um germe de movimento que só secundariamente se desenvolve em percurso objetivo" (MerleauPonty 10, p. 111). Do ponto de vista clássico, um movimento real somente pode atualizar o movimento possível: que todo movimento seja espacial significa que se ajusta à lei da exterioridade que determina o sistema de todo movimento possível. Da perspectiva fenomenológica, o movimento real abre ou instaura um campo de movimento possível.

Ora, podemos notar especialmente nos últimos cursos e escritos de Merleau-Ponty indicações de uma concepção do movimento ainda mais radical que a noção fenomenológica referida acima: um movimento real 
que não entra no sistema do possível, tampouco abre apenas um campo de possibilidades. Este movimento quebra todo sistema ou campo de movimento possível, introduzindo então, não uma impossibilidade de sair, de mistério ou de afastamento - tampouco uma "impossibilidade de princípio" como aquela que Merleau-Ponty relacionava com o conhecimento acabado do mundo na Fenomenologia da Percepção -, mas sim uma impossibilidade violenta e destrutiva. ${ }^{6}$ Um movimento que, como o próprio nascimento e a aparição no mundo de uma nova vida, desconhece todo passado e não tem "todo o futuro pela frente", mas aponta em direção a seu próprio final. ${ }^{7}$ Assim, em algumas das escassas referências à questão, Merleau-Ponty afirma que "vivo em uma atmosfera de morte em geral; (...) minha vida tem uma atmosfera social assim como um sabor mortal" (Merleau-Ponty 10, p. 375).

Quando se agrega a variável temporal à análise do movimento, é possível reconhecer a singularidade desta terceira figura. No caso do espaço objetivo, o movimento segue a lei da exterioridade e instaura assim a regularidade temporal da sucessão em sua clássica figura linear. No que diz respeito ao movimento em sua noção fenomenológica, por sua vez, o movimento vivido estabelece relações internas de montagem entre as partes do espaço de tal modo que o tempo sucessivo e linear cobra uma nova dimensão onde coexistem em simultaneidade os horizontes passados e futuros: o instante se "expande" no sentido vertical e a linha se anula em uma rede. Na Fenomenologia da Percepção Merleau-Ponty analisou o gráfico de Husserl da rede do tempo mostrando sua eficácia e suas limitações como modelo da experiência tal como é vivida (MerleauPonty 10, Parte III, cap. 2). Essa rede deveria ser vista, na leitura proposta por Merleau-Ponty, mais como a abreviação de um modelo tridimensional feito de camadas transparentes de retensões e protenções localizadas atrás do presente, transluzindo-se até a opacidade (Merleau-Ponty 10, p. 425). ${ }^{8}$
Essa interpretação em termos de transparência tem a virtude de mostrar que coexistem o presente, o passado retido e o futuro visado, o que podemos recordar e antecipar, porém, ainda além se transluz também o que não podemos recordar nem antecipar. O que se vê coexiste com o visto, com o visível e também com o invisível, tendo aqui o invisível a conotação, tanto para Merleau-Ponty quanto para Husserl, dos horizontes da "natureza". Acerca dos horizontes do passado longínquo, Husserl escrevia nas Meditações Cartesianas, obra emblemática da etapa "genética" de sua fenomenologia:

Nesta experiência [transcendental do eu] é o ego originariamente acessível a si mesmo. Porém essa experiência só oferece, em todo caso, um núcleo de realidade experimentada de um modo "propriamente adequado" [...] enquanto que além dessa atualidade só se estende um indefinido horizonte universal e presuntivo [ao qual pertence] o passado do eu, na maioria das vezes completamente obscuro (Husserl 8, pp. 64, 65).

Levando-se em conta o contexto do parágrafo citado, podese considerar que esse passado obscuro, ao qual Husserl alude aqui, remete à nossa primeira infância. Contudo, mais tarde, nos manuscritos da década de 1930, Husserl se perguntará: "até onde se estende tal reconstrução [da análise fenomenológica] com relação ao nascimento (ou seja, eventualmente, antes do nascimento)?”. A pergunta aponta mais especificamente na seguinte direção: "não somos então impulsionados para trás, dos homens aos animais, às plantas, [...] até uma consideração transcendental-subjetiva que, reconstruindo, avança retrospectivamente até seres-sujeitos de diferentes níveis de ordenação com uma consciência instintiva e uma comunicação instintiva?” (Husserl 7, Apêndice XLVI). 
Merleau-Ponty em sua Fenomenologia da Percepção parece compartilhar essa concepção da natureza como passado obscuro e misterioso: a opacidade da natureza resultaria da acumulação de camadas transparentes de tempo. Assim é que o filósofo pode afirmar, por exemplo, que "o mundo natural (...) sempre transparece no outro [o mundo cultural]" (Merleau-Ponty 10, p. 308). Tratar-se-ia em tal caso de uma opacidade obtida gradualmente por distanciamento e indefinição, uma espécie de tranquilo anoitecer no qual a consciência adormeceria nos braços de sua mãe, a natureza. Essa metáfora maternal poderia não resultar tão distante do modo de pensar do próprio Merleau-Ponty, se recordamos que a Fenomenologia da Percepção caracteriza a consciência como "filha do mundo": "A consciência não se atribui este poder de constituição universal apenas quando se passa em silêncio o acontecimento que constitui sua infraestrutura, que é seu nascimento. (...) Nascer é ao mesmo tempo nascer ao mundo e nascer do mundo" (Merleau-Ponty 10, p. 460). Contudo, as ilusões da Fenomenologia da Percepção com respeito à questão do mundo natural podem resultar problemáticas no contexto mais geral da obra, e provavelmente devem ser consideradas um esboço da concepção mais articulada e significativa da natureza, a qual progressivamente passará ao primeiro plano no pensamento posterior do filósofo.

Merleau-Ponty salienta na obra de 1945 que a concepção fenomenológica do tempo - ligada intimamente às do espaço e da natureza - é demasiadamente modesta em sua consideração do futuro: o diagrama retilíneo husserliano se estende até abaixo das linhas oblíquas das retensões e presuntivamente se completa acrescentado acima "a perspectiva simétrica das protensões" (Merleau-Ponty 10, p. 425). Embora o tempo se abra desde um presente vivente, absoluto, um acontecer que ata completamente a rede e que não pode ser localizado como qualquer outro ponto de cruz "no tempo", a afirmação da "originalidade de cada perspectiva" concorre no esquema husserliano com um visível nivelamento do tempo: o futuro é acrescentado como "um passado porvir" (Merleau-Ponty 10, p. 431). Isto é assim desde que "algumas linhas intencionais traçam de antemão pelo menos o estilo do que virá (embora sempre esperemos, e sem dúvida até a morte, ver outra coisa aparecer)" (Merleau-Ponty 10, p. 424). Ainda que a perspectiva fenomenológica leve em consideração o movimento desde o corpo vivido como abertura do espaço e do tempo, a realidade do movimento é, todavia, coagulada no marco de um sistema de possibilidades de movimento. Certamente, nesse caso não se trata de um sistema espaçotemporal a priori, fechado e sem lugares ou direções distinguíveis, porém, o espaço fenomenológico somente pode abrir-se sob a condição de configurar a cada vez, em cada movimento e com cada nova perspectiva um sistema de possibilidades que compõe harmonicamente todos os lugares e todos os tempos. "Todos" não significa "todos os pensáveis ou concebíveis", mas "todos os que podem ser vividos" ou "todos os visíveis", quer dizer: os que são invisíveis desde meu presente ou desde minha perspectiva. A definição fenomenológica do movimento fracassa porque se o movimento surge a partir do eu, mesmo sendo este eu concebido como eu-corpo ou poder de movimento, todo espaço que se abre volta a cada vez a fechar ou cristalizar o movimento que o abre.

O espaço vivido, certamente, não é limitado pelo infinito do possível pensado, mas se abre ao possível vivido, ao invisível para mim agora, porém, visível para mim no passado e no futuro, e também ao visível para os outros. Contudo, essa abertura comporta uma nova limitação: o espaço se abre ao invisível que eu nunca vi ou verei, ou inclusive que ninguém viu ou verá, porém, essa invisibilidade é concebida ainda como um espaço contínuo e adjacente ao espaço visível. Trata-se de um espaço invisível que acolhe o visível: nunca o espaço se abre de tal modo que a visibilidade se interrompa, o invisível não impossibilita a continuidade 
da visão e o que foi visto antes nunca desaparece sem deixar rastro. A perspectiva fenomenológica considera que o movimento de meu corpo abre o espaço, porém acomoda o movimento ao espaço aberto e considera o último como uma abertura feita "na medida" do corpo que o abre. Pelo contrário, na experiência mesma, este abrir-se do espaço é na realidade vivido como um movimento transbordante e excessivo, quando não relativo e limitado, afortunado e falido, gozoso e agônico. O mundo ou o espaço que nosso movimento corporal abre e ao qual se abre "nunca está completamente feito" (Merleau-Ponty 10, pp. 20, 341 e ss.) nem se acomoda à sua medida ou à sua "capacidade de fazer presa": meu movimento sempre é efetivamente impulsionado e interrompido pela força de outros movimentos imprevisíveis e mais poderosos.

Fiel à descoberta fenomenológica do movimento que abre o espaço ao invés de acontecer no espaço, Merleau-Ponty, seguindo Husserl, deve dar lugar neste espaço a uma diversidade de espaços que se abrem a partir de uma diversidade de corpos próprios, uma diversidade de comunidades culturais e de gerações. O espaço se abre a partir daqui, este centro em direção ao qual todos os olhares das coisas convergem como os raios de uma roda quando os olho. Porém, a roda da experiência não está perfeitamente centrada na medida em que as coisas não me olham somente, mas sempre estão desviando seu olhar a outro, situação da qual foi especialmente consciente Sartre ao escrever que "o próximo é a fuga permanente das coisas a um termo que tanto capto como objeto a certa distância de mim quanto me escapa enquanto desdobra em torno de si suas próprias distâncias". O próximo abre outro espaço "e este espaço é feito com meu espaço". Então, abrir o espaço ou desdobrá-lo é ao mesmo tempo abrir uma rachadura, uma fuga ou "uma hemorragia" no espaço já desdobrado por outro e expor-se a sofrer continuamente essas mesmas avarias e catástrofes, tal como agudamente o expressara Sartre
(Sartre 16, pp. 284 e ss.). Em certas passagens de sua Fenomenologia da Percepção, contudo, Merleau-Ponty parece manter-se próximo da ortodoxia husserliana afirmando que a multiplicidade e a diversidade de espaços coexistem em simultaneidade, compondo-se e compondo o espaço único do mundo, porquanto compartilham o passado comum da natureza como "única mãe", que ninguém conheceu nem pode conhecer, mas que lhes deu vida a todos:

A novidade da fenomenologia não estava em negar a unidade da experiência, mas em fundamentá-la diferentemente do racionalismo clássico. (...) $\mathrm{O}$ espaço natural e primordial não é o espaço geométrico e correlativamente a unidade da experiência não vem garantida por um pensador universal; (...) não me libera de cada meio particular ainda mais porque me ata ao mundo da natureza (...) que os envolve a todos (Merleau-Ponty 10, p. 308).

Merleau-Ponty nunca abandonou totalmente essa primeira intuição fenomenológica de uma unidade primordial de toda experiência, dos diversos sujeitos e comunidades, e inclusive de todos os seres vivos, porém, sem dúvida chegou a concebê-la de outro modo quando escreveu cerca de uma década mais tarde que embora "os homens e o tempo, o espaço sejam feitos do mesmo magma" ao modo de uma "montagem [emboîtement: incorporação, anexação), há uma sorte de transbordamento [empiétement] dos corpos uns sobre os outros, o que acontece a um, sua vida e sua morte, metamorfoseia a duração, a idade do outro" (Merleau-Ponty 13, p. 211). A unidade do tempo deve ser entendida sob esta perspectiva, como "a coexistência de tempos incompossíveis" (Merleau-Ponty 13, p. 207). Na percepção coexistem perspectivas que são ao mesmo tempo “incompossíveis e inseparáveis, e é nessas condições difíceis que buscamos o que conforma o tecido do mundo" (Merleau-Ponty 14, p. 154). O presente 
é agora caracterizado como présent-gigogne (o que poderia ser traduzido por "presente desdobrável", mas também por "presente frutífero"). ${ }^{9}$ À luz desses cursos tardios a respeito do tempo, os "filhos" deste presente frutífero o colocam em questão, e seu desdobrar o transforma em uma dobra, mas de uma estrutura sem um centro fixo ao qual possa regressar: "o passado que [o presente] contém o descentra, é outro mundo" (MerleauPonty 13, p. 207). A partir das notas posteriores à Fenomenologia da Percepção, o eu-corpo como esquema motriz não fornece a definição mais própria do movimento como aquele ponto zero desde o qual se abrem ou se desdobram o tempo e o espaço, mas o movimento pode ser concebido de forma mais radical, como movimento de nascer ou brotar que não abre o espaço, porém, o faz explodir, multiplica-o, coloca-o finalmente em movimento no sentido próprio: faz real o impossível, não somente o inconcebível ou o que ninguém nunca pôde ver, mas o que não pode existir no mundo como plexo do existente ou como alguma forma de totalidade.

\section{O corpo vivente e movimento do nascer}

Neste sentido, podemos afirmar que aquele "mundo em estado nascente" correlato de um "sujeito em estado nascente", cujo propósito de Merleau-Ponty era redescobrir, segundo afirmavam as primeiras páginas da Fenomenologia da Percepção, encontrará sua forma mais apropriada na natureza cujo "sentido originário" o filósofo persegue nos cursos sobre La Nature (1956-60). Trata-se de um mundo cujo ser consiste em um movimento nunca fechado ou totalizado, associado por MerleauPonty diretamente ao movimento da vida entendido, por sua vez, em termos de brotar, crescer e nascer: "Em grego a palavra natureza vem de phýo, que faz alusão ao vegetal; a palavra latina vem de nascor, nascer, viver. Há natureza onde há uma vida que tem sentido, ainda que não haja pensamento" (Merleau-Ponty 15, p. 19). Esta mesma ideia está presente na sentença de Lucien Herr, inspirada em Hegel, a qual Merleau-Ponty gosta de citar em seus cursos: "a natureza está sempre em seu primeiro dia". A natureza é nascimento, e o nascimento é o movimento que caracteriza a vida ou o movimento vital por antonomásia. Em um sentido análogo o filósofo afirmará em seus cursos que "a vida não é como na definição de Bichat, o conjunto de funções que resistem à morte, mas uma potência de inventar o visível". ${ }^{10}$

Merleau-Ponty efetivamente procura, então, pensar o corpo vivente e a vida mesma a partir deles mesmos, e não sempre e somente a partir de um jogo de oposições que os traem por excesso ou por falta. De acordo com a interpretação aqui sugerida, eles recebem uma determinação positiva em termos de um movimento originário que é anterior a todo ente que se move e a todo ser concebido no sentido unitário, total ou estático, já que se trata em última instância do movimento de nascer ou brotar. Neste sentido, Merleau-Ponty propõe que haja um tipo de ser interrogativo que define a vida, mais do que um ser positivo que lhe seja próprio (Merleau-Ponty 11, p. 139). Assim como o movimento de nascer não acontece ao ser, mas lhe é prévio - "faz ser" -, esta interrogação da vida permite ser entendida naquele sentido radical pelo qual Merleau-Ponty se refere, nas primeiras seções do Visivel e o Invisível, a um modo originário da interrogação que não deriva do indicativo (Merleau-Ponty 11, p. 171). Referindo-se aos cursos de Merleau-Ponty acerca das investigações embriológicas, Bimbenet escreve:

Contra a imobilização da vida perpetrada pelo mecanicismo e pelo finalismo, Merleau-Ponty afirma que "não há um ser positivo, mas um ser interrogativo que define a vida". $\mathrm{O}$ organismo está sempre além de si mesmo, inclinando em direção ao futuro, porém sem que este futuro possa ser prefigurado de antemão sob a forma de um fim determinado. 
"Há uma falta constitutiva que não é disto ou daquilo", diz Merleau-Ponty, e assim, pois, há uma invenção do possível (Bimbenet 3, p. 156).

Bimbenet persegue essa noção da vida, ao longo das páginas de La Nature, como "ser incoativo" que sempre está começando (assim como se fala de "verbos incoativos", que se referem ao começo de um processo, tais como "florescer"). A vida é "iminência", "vazio do que virá", "não ser operante" e "produtividade originária" nas definições de Merleau-Ponty citadas pelo autor, que as resume na noção de "advento" (événement), como "instituição e criação de sentido, abertura de dimensões inéditas" (Bimbenet 3, p. 146). Os movimentos da carne que descrevem as páginas do Entrelaço-o Quiasma do Visível e o Invisivel também podem ser lidos nesta chave: as invaginações, dobras, deiscências, brotos, reentrâncias, multiplicações de folhas e de lábios que tornam sentiente o espaço sensível, assim como a sublimação do espaço sensível em pensamento, são descritos por Merleau-Ponty mediante uma profusão de figuras vegetais e sexuais que ilustram a cada passo o nascimento de novas dimensões do ser: um ser que é em si mesmo somente este movimento de fazer-se, desdobrar-se, diferenciar-se e multiplicar-se.

Ora, já na Fenomenologia da Percepção pode-se ler, embora certamente em referências intermitentes, que o movimento vivido é vislumbrado como devedor deste movimento mais originário da vida, a qual é descrita mais fielmente pela última produção do filósofo. Assim, afirma Merleau-Ponty em 1945, por exemplo: "Eu não sou o autor do tempo, assim como não sou autor das batidas de meu coração, não sou eu quem toma a iniciativa da temporalização; eu não escolhi nascer, e uma vez nascido, o tempo funde-se através de mim, o que quer que eu faça". A propriedade desta temporalização vital se mostra em que a novidade ou espontaneidade que pode introduzir minha ação sempre é devedora de uma originalidade mais radical própria à vida:
Uma 'espontaneidade' adquirida de uma vez por todas que 'se perpetua no ser em virtude do adquirido' (...) não se pode deduzir o tempo da espontaneidade. (...) a potência de ir além (...) nos é dada com a temporalidade e com a vida. Nosso nascimento, ou, como diz Husserl em seus inéditos, nossa 'generatividade', funda ao mesmo tempo nossa atividade" (Merleau-Ponty 10, p. 435).

Assim, se em sua obra de 1945 Merleau-Ponty busca na fenomenologia uma definição positiva do corpo em função de um modo original e originário de movimento, o filósofo já avança na direção de superar ou radicalizar a visão fenomenológica clássica ao discernir que o modo mais originário e o sentido mais próprio do movimento corporal é o nascer. Assinalamos anteriormente que naquela obra é sublinhado o fato de que a consciência não pode ser qualificada como constituinte do mundo, afirmando que, ao contrário, ela nasce no mundo: seu nascimento constitui "sua infraestrutura" mesma (Merleau-Ponty 9, p. 517). Essa consciência "nascida" é propriamente aquilo que Merleau-Ponty propunha descrever desde o prólogo de sua obra ao falar do sujeito em "estado nascente", e é, por sua vez, esse sujeito "nascente" o que deveria assim ser identificado com o corpo "vivente", se o nascer fosse o mais próprio do viver. A exclusão da possibilidade de um sujeito constituinte, afirma Merleau-Ponty, deriva da afirmação de "um mundo que nunca é, como disse Malebranche, mais que uma obra inacabada" paralela a de um corpo que, segundo a fala de Husserl citada por Merleau-Ponty, "nunca está completamente constituído": um corpo que não apenas nasceu, mas que, como vivente, nunca deixa de nascer (Merleau-Ponty 9, p. 465). Também escreve Merleau-Ponty: "A esta unidade aberta do mundo deve corresponder uma unidade aberta e indefinida da subjetividade", quer dizer, um sujeito que poderia ser caracterizado como perpetuamente nascente, 
tal como continua propondo o resto do capítulo citado - "O cogito" -, que inclui um parágrafo referido especificamente ao nascimento, o qual vale a pena citar in extenso neste contexto:

Certo dia e de uma vez por todas algo começou que, mesmo durante o sono não pode mais parar de ver ou de não ver, de sentir ou de não sentir, de sofrer ou de estar feliz, de pensar ou de descansar, em suma, de se 'explicar' com o mundo. Aconteceu não um novo lote de sensações ou de estados de consciência, nem mesmo uma nova mônada ou uma nova perspectiva, já que não estou fixado em nenhuma e posso mudar de ponto de vista, sujeito apenas a sempre a ocupar um ponto de vista e a ocupar somente um a cada vez - digamos que aconteceu uma nova possibilidade de situações. O acontecimento de meu nascimento não passou, não caiu no nada à maneira de um acontecimento do mundo objetivo, ele envolvia um porvir (...) Doravante havia um novo ambiente, o mundo recebia uma nova camada de significação. Na casa onde nasce uma criança, todos os objetos mudam de sentido, eles se põem a esperar dela um tratamento ainda indeterminado, alguém diferente e alguém a mais está ali, uma nova história (...) acabou de ser fundada, um novo registro está aberto. Minha primeira percepção, com os horizontes que a rodeiam é um evento sempre presente (Merleau-Ponty 9, p. 465, 466).

Esta passagem comporta ao menos três particularidades que podem se destacar no marco da análise aqui proposta. Em primeiro lugar, o fato de que esse movimento de nascer, próprio ao eu-corpo, parece transcender o "movimento vivido" no sentido fenomenológico restrito, como mero desdobrar de perspectivas já latentes ou de novas perspectivas que reestruturam os horizontes já sedimentados e compõem sempre um "arco intencional" harmônico, cuja compossibilidade é garantida pelo mundo, entendido como totalidade ao menos presuntiva. Trata-se, afirma o texto, da aparição de novos campos de possibilidades, quer dizer, de uma peculiar "atualização" (no sentido de "fazer-se") do que antes não era possível, o que não entrava no mundo como campo total de possibilidades, e que agora é perturbado, transformado ou criado. Em segundo lugar, este nascimento como realização do impossível e criação ou invenção do possível acontece simultaneamente como movimento de fazer-se ou de nascer do corpo e do mundo. Embora no parágrafo citado se sublinhe a direção do sujeito ao mundo (o mundo "recebe uma nova dimensão de sentido"), podemos recordar outras afirmações mais enfáticas que se referem ao nascimento do sujeito no mundo e a partir do mundo: "eu sou uma dobra [do ser ou do mundo] que se fez e que pode desfazer-se" (Merleau-Ponty 9, p. 249). Em terceiro lugar, este movimento de nascer não é somente remetido ao passado como em outras ocasiões quando só se pretendia limitar o poder constituinte do sujeito opondo-lhe a precondição de um passado natural ou absoluto que às vezes se deslizava equivocamente a determinações anátomo-fisiológicas. Aqui se fala de um corpo nascente, cuja primeira percepção, aquela inauguração de um futuro não antecipável ou aquele surgir do inédito, "é um evento sempre presente", correlato indissociável de um mundo que está "sempre no primeiro dia".

No marco da linha interpretativa aqui proposta, podem ser compreendidas também as frequentes alusões merleau-pontianas ao corpo definido em comparação com a obra artística: "não é com o objeto físico que se pode comparar o corpo, mas com a obra de arte" (MerleauPonty 10, p. 167). A comparação aponta, nas análises de Merleau-Ponty, especialmente para a questão do "sentido aderente" ao suporte material ou aos "conteúdos sensíveis": "é neste sentido que nosso corpo é comparável à obra de arte: é um nó de significações vivas" (Merleau-Ponty 10, p. 168). Contudo, pode-se ver ainda outro sentido desta frequente comparação do 
corpo com a obra de arte, nem sempre explicitado por Merleau-Ponty, porém sempre latente para o leitor; e este é o mais comum à "criação" artística. É justamente esse aspecto o que aparece mencionado no prólogo da Fenomenologia da Percepção em referência ao mundo e à filosofia: “o mundo fenomenológico não é a explicitação de um ser prévio, mas a fundação (...) do ser; a filosofia não é o reflexo de uma verdade prévia, mas, como a arte, a realização de uma verdade". Este mundo "e a filosofia que o faz vir à existência manifesta não começa por ser possível: é atual ou real". Trata-se neste caso, conclui o parágrafo, de "um ato violento que se verifica exercendo-se" (Merleau-Ponty 10, p. 20).

\section{THE LIVING BODY AND THE MOVEMENT OF THE LIFE IN M.}

\section{MERLEAU-PONTY AND R. BARBARAS}

Abstract: Firstly, the analyses here proposed focus on the interpretation of the Merleaupontyan corpus proposed by R. Barbaras in his Introduction à une phénoménologie de la vie, according to which the oscillations and ambivalences of Merleau-Ponty's reflection on the body could be explained by the neglect of its basic living character. Secondly, we approach Merleau-Ponty's philosophy as the project of finding in the body an original and absolute modality of movement as an opening of possibilities, a movement in which both the object that moves and the space that is opened by the movement are founded. Thirdly, by focusing on the notion of birth we propose that this singular modality of movement searched by Merleau-Ponty find its proper characterization as natural and vital movement, conciliating at least partially the perspectives of both philosophers.

Keywords: Merleau-Ponty - Barbaras - Mouvement - Life - Corporeality

\section{REFERÊNCIAS BIBLIOGRÁFICAS}

1. BARBARAS, R., Introduction à une phénoménologie de la vie, París, Vrin, 2008. 2 . , Le tournant de l'expérience. Recherches sur la philosophie de MerleauPonty, París, Vrin, 1988.

3. BIMBENET, E., "L'être interrogatif de la vie: l'historicité de la vie dans les cours du Collège de France 57-58”, en Chiasmi International, París, Mimesis/ Vrin, II, 2000

4. DESCARTES, R., Los principios de la filosofia, Buenos Aires, Losada, 1997.

5. GARCÍA, E. A., "La phénoménologie de l'expérience corporelle au delà du sujet et de l'objet”, In Chiasmi International, Paris, Mimesis/Vrin, IX, 2007.

6. HUSSERL, E., La tierra no se mueve, Madrid, Editorial Complutense, 1995.

7.___ Zur Phänomenologie der Intersubjektivität (Gesammelte Werke Husserliana XV), The Hague, Martinus Nijhoff, 1973, Apéndice XLVI.

8. , Meditaciones cartesianas, México, FCE, 1996.

9. MERLEAU-PONTY, M., Phénoménologie de la perception, París, Gallimard, 1945.

10. ___ Fenomenología de la percepción, Barcelona, Planeta, 1994.

11. __ Le visible et l'invisible. Suivi de notes de travail, París, Gallimard, 1964.

12. ___ L' oeil et l'esprit, París, Gallimard, 1964.

13. ___ Notes de cours au Collège de France 1958-1959 et 1960-1961, París, Gallimard, 1996.

14. ___ Signes, París, Gallimard, 1960

15. __ La nature. Notes de courses du Collège de France, París, Éditions du Seuil, 1995.

16. SARTRE, J.-P., El ser y la nada, Barcelona, Altaya, 1993.

\section{NOTAS}

1. Na mesma nota citada por Barbaras, Merleau-Ponty reivindica um certo "valor do dualismo": segundo o comentador "se trata de pensar uma univocidade que não comprometa a diferença da consciência" (Barbaras 1, pp. 80, 81).

2. Veja-se, por exemplo, Merleau-Ponty 10, pp. 288, 100.

3. No mesmo sentido, escreve Merleau-Ponty: "Meu corpo não é simplesmente um percebido entre os percebido, ele é medidor de todos” (Merleau-Ponty 11, p. 302); “A experiência de minha própria carne (...) me ensinou ela não nasce não importa onde, que ela emerge na recessão de um corpo" (Merleau-Ponty 11, pp. 24, 25).

4. Segundo afirma Merleau-Ponty, só porque "meu corpo que é um dos visíveis se vê também a si mesmo" pude se realizar "a milagrosa promoção do Ser à 'consciência', ou como dissemos, a segregação do 'dentro' e do 'fora”' (Merleau-Ponty 11, pp. 157, 158). 5. A respeito, cf. García 5, p. 9. 
6. "É essencial para a coisa e para o mundo o que (...) nos permitam algo mais por ver" (Merleau-Ponty 1, p. 146).

7. A referência a um fundo indefinido aparece nas últimas páginas de $O$ Olho $e O$ Espírito (Merleau-Ponty 8).

8. Assim se afirma que ao recordar um momento, A é dado "por transparência através de $A^{\prime}(. .$.$) e assim sucessivamente como vejo o ladrilho através das massas de água que$ deslizam sobre ele" (Merleau-Ponty 10, p. 425).

9. Também um presente de "imbricação", "montagem", "acoplamento" ou "embutimento": gigogne se aplica às mães de muitos filhos, aos móveis e utensílios desdobráveis e às bonecas russas.

10. O texto correspondente aos cursos sobre a natureza é citado em Bimbenet 3, p. 161.

\section{A EXPERIÊNCIA DA FALTA E O MISTÉRIO DO DESEJO}

Silvana de Souza Ramos*

Resumo: O artigo analisa a importância da leitura da obra de Merleau-Ponty no interior da construção da filosofia de Barbaras. Por um lado, trata-se de compreender os limites do corpo próprio para dar conta do a priori correlacional exigido pela fenomenologia. Por outro lado, buscamos desvelar, nos desdobramentos da filosofia da vida proposta pelo filósofo, um horizonte de novos problemas, referidos especialmente à descrição da peculiaridade do desejo humano frente à vida entendida num sentido mais geral. Palavras-chave: Barbaras, Merleau-Ponty, vida, desejo, intencionalidade, mundo.

1. A originalidade de um pensamento pode ser definida por sua capacidade de revigorar certos temas herdados da tradição, conferindolhes um sentido ainda não explorado, uma direção ou um alcance antes invisível. Isso não significa apenas dar um novo significado a determinado conceito ou, ainda, inventar novos conceitos, mas, sobretudo, retomar uma questão - desvinculando-a de certos pressupostos naturalizados ou cristalizados pelo pensamento vigente - de modo a produzir uma resposta inédita. Por um lado, isso exige que o pensador se situe na perspectiva de uma determinada corrente filosófica: o pensador é inicialmente o aprendiz de certa maneira de transitar pelo terreno da idealidade. Por outro lado, não basta incorporar esse estilo: é preciso desdobrá-lo, isto é, assumir a tarefa de pensar por si mesmo. É por isso que uma tradição filosófica só pode enriquecer, ou seja, ampliar nossa potência de pensar, na medida em que se diversifica por meio do trabalho de pensadores individuais.

* Pós-doutoranda pelo Departamento de Filosofia da USP (bolsista Fapesp). 